\title{
The Statistics in Daily Life
}

\author{
Liujia Li $i^{1,2}$ \\ ${ }^{1}$ China Coal Aerial Photogrammetry and Remote Sensing Group Co. Ltd., Xian, Shaanxi 710199 \\ ${ }^{2}$ Shaanxi Provincial Geo-Spatial Information Engineering Technology Research Center, Xian, \\ Shaanxi 710199
}

423037603@qq.com

Keywords: The enterprise financial statistics; Statistics of fix assets; Financial statistics; The labor statistics.

\begin{abstract}
Statistics can be encountered in the life and work of all kinds of digital integration and to analyze its characteristics by certain rules. Such as the business planning, asset evaluation, fixed assets, personnel statistics are using statistics form statistical investigation method achieve the purpose of prediction their development tendency. This article will explain the various types of the application of statistics through the examples in real situation. And we can feel more real and appropriate that statistics work can help us more scientific to evaluate things, and let us realize that other management accounting cannot replace the importance of the statistics' work, thus we will strengthen the attention to the statistics and let the statistics play its role.
\end{abstract}

\section{The Concept of Statistic}

The famous statistician C. R. Rao said: "In the ultimate analysis, all knowledge in history; in the abstract sense, all science is mathematics; in a rational world, all judgment is statistically." In today's world, the statistic has already permeated in science, engineering course, agricultural, medical, arts and other courses, and plays a leading role in dealing with modern science and the most important and most diverse subjects.

From the professional research, statistics are everywhere around the managers judgment and the life that occupy the home of ordinary people, the generalized characteristic of statistics is important for determining the general statistical category. Generalized statistics is our general sense of statistics, not only include what we call the statistical work, learning and application of various statistical methods, but also include the statistical behaviors and activities in the people's daily life, it can be understood as the statistics will cover all of the statistical phenomenon and the behavior [1].

Statistics is the number of investigating things phenomenon to study a particular phenomenon, it's essential is the survey of the number. Put down the block of non-governmental statistical and popularization, from the reality, narrow statistics has been already conventionalized understands as the professional statistician and statistical work. What we learn in school is statistics, and what we do in the post is statistical work, statistical work and statistics has already thorough popular feeling. Current Statistics detailed rules for the implementation of the People's Republic of China indicate that: The statistics is using all kinds of research method of the national economic and social development of statistical investigation, analysis, providing statistical data and advice, it's the floorboard of the exercise statistical supervision, and other activities.

\section{The History of Statistic}

The history of statistical, national demand for statistical work is increased with the development of productivity and the change of the social system. For example, the unity of the state of Qin, promoted the development of the feudal economy and culture, unified management of national finance, economy and culture, unified management of national finance and economy needs lead to the development of the statistical work at the same time.

At the end of the seventeenth century, the earliest statistics produced, and called the state and 
political arithmetic, which is structured to use statistical methods of a series of data operation, in order to get a conclusion. In order to fully grasp the country's national power for comparing with other countries, facilitate the calculation of statistics is not a simple individual countries, but in other countries and the investigation of the basic situation and development trend. At this point, we not only need the data, but also need for statistical work of the experiment to develop a scientific theory and method of statistics.

Modern statistics is calculated firstly, it is for calculation of the countries concerned matters, the purpose is to grasp the current national conditions, national strength and national development, serving the country management. Statistics of arises at historic moment is the need of national management, emergence and development of the statistics is made up of social productivity development and national function of expanding.

Starting from the research object and task of statistics, research methods of modern statistics mainly is to study and improve the traditional statistical methods, using the methods of mathematical statistics and mathematics achievement at the same time, in addition will also adopt the accounting principles, methods and classification standard will link up statistical accounting and accounting, play a very important role to lighten the burden at the grass-roots level, and overcome the macroscopic accounting from microcosmic accounting status and make full use of value indicators and other departments of the accounting information.

\section{The Application of Statistical}

As professionals working in the field of statistics, we need to understand and grasp the basic theory of statistics and statistical methods. In some specific areas in economic and social activities of phenomena as the research object of statistical activities are rich in content and the species are diversity, such as energy statistics, financial statistics, statistics of investment in fixed assets, foreign economic and trade statistics, financial statistics, population statistics, labor wage statistics, social statistics, statistics, resources and environment statistics and so on. Now, here we will introduce the statistical type close to our life one by one.

The Enterprise Financial Statistics. Enterprise financial statistics is by the value calculation, reflect the status of enterprise business activities and regular statistical method [2].

On assets and equity in the process of production and operation, labor cost and labor achievements and its distribution in statistics and analysis mainly using the assets and liabilities, cost, profit and loss and economic categories [3, 4]. Analysis and statistics on assets and equity in the process of production and operation, labor cost and labor achievements and its distribution, including enterprise assets and liabilities of financial statistics, and losses of the enterprise financial statistics, salary, welfare, value-added tax financial statistics and so on.

Statistics of Fix Assets. Fixes assets are an important part of national wealth which includes created by social labor, working of all sorts of labor resources and may need to use products [5]. Many enterprises due to the expansion of fixed assets, rebuilding and purchasing, not only absolute the fixed assets, but also greatly degree of enterprise fixed assets to update, and it can't come out from the reflected in the dynamic index of the fixed assets. So it is necessary to calculate the updating coefficient and removal coefficient of enterprises. Fixed assets depreciation and the depreciation rate can't reflect the degree of wear and tear of a fixed asset, so there also has the wear coefficient, used to show the condition of fixed assets. And we cannot increase the fixed assets and use the existing effectively.

Financial Statistics and Labor Statistics. Financial statistics is to financing tool refinancing forms of main elements such as financial institutions, financial market statistics, is all sectors of the economy's stock of financial assets and financial liabilities and traffic statistics [6]. According to

《The China labor statistical yearbook》 from year 2004 to 2008 , we can get the number of the laborers engaged in the financial sector in China from 2003 to 2007. 
Table 1 The total number of China's financial sector workers at the end of year 2003-2007

\begin{tabular}{|c|c|c|c|c|c|}
\hline \multirow{2}{*}{ Year } & \multirow{2}{*}{ Financial (ten thousand people) } & \multicolumn{4}{|c|}{ Classification (ten thousand people) } \\
\cline { 3 - 6 } & & Bank & Insurance & Securities & Other financial \\
\hline 2003 & 286.2 & 244.1 & 6.3 & 32.0 & 3.7 \\
\hline 2004 & 288.9 & 237.5 & 6.7 & 38.5 & 4.2 \\
\hline 2005 & 295.0 & 240.5 & 6.2 & 44.1 & 4.2 \\
\hline 2006 & 299.9 & 241.6 & 6.8 & 47.0 & 4.4 \\
\hline 2007 & 311.1 & 245.7 & 7.6 & 53.0 & 4.8 \\
\hline
\end{tabular}

From table 1 shows, whole workers is higher growth rate of China's financial industry is rising steady which is from 2003 in 2.862 million to 2007 in 3.111 million, and the up is nearly $8.7 \%$. To put this in perspective, securities and other financial industry including business, leasing and so on also showed a increased trend, but the insurance industry in 2005 workers number appeared a negative growth, and then began to pike up, the number of workers of banking sector basic parallel statistical index curve and financial sector, in the process of salary calculation, calculating variable using mathematical formula, make good use of statistics to reasonable set the proportion of employee compensation which play an important role in the development of the company. To focus on the economy, management class in reality, the actual application ability, in the work and by analyzing the list, addition, subtraction, multiplication and division pattern elementary methods, can express the overall, intuitive understanding of the data to help people solve problems [7, 8].

By the China labor statistical yearbook can get from 2004 to 2007, our country financial industry average annual salary of workers Specific data in table 2.

Seen from above, total average wage of finance is generally on the raise, the average wage level of the banking industry and the overall financial sector's average wage are roughly the same. Average wage standard of the insurance industry is significantly higher than the industry average [ 9 , $10]$.

As the research from 2004 to 2007, changes in the general worker average wage of China's financial industry, the relevant data in 2004 and 2005 average to be the base period, the related number averaged 2006 and 2007 to be the reporting period. Sum the banking insurance securities and trust funds and other related summary and get the Table 3.

Table 2 The average wage of China's financial industry by year 2003-2007

\begin{tabular}{|c|c|c|c|c|c|}
\hline \multirow{2}{*}{ Year } & \multirow{2}{*}{ Financial(CNY) } & \multicolumn{4}{|c|}{ Classification(CNY) } \\
\cline { 3 - 6 } & & Bank & Insurance & Securities & Other financial \\
\hline 2004 & 26982 & 26349 & 50529 & 25185 & 41795 \\
\hline 2005 & 32228 & 32236 & 56418 & 27104 & 48361 \\
\hline 2006 & 39280 & 39096 & 85522 & 31774 & 56856 \\
\hline 2007 & 49435 & 48939 & 142979 & 36307 & 69580 \\
\hline
\end{tabular}

Table 3 Sum of workers and wage In every category in financial in China at base period and reporting period

\begin{tabular}{|c|c|c|c|c|c|c|c|}
\hline \multirow{2}{*}{$\begin{array}{c}\text { Industry } \\
\text { category }\end{array}$} & \multicolumn{2}{|c|}{$\begin{array}{c}\text { Worker number }(\text { ten } \\
\text { thousand people })\end{array}$} & \multicolumn{2}{|c|}{$\begin{array}{c}\text { Average wage } \\
(\mathrm{CNY})\end{array}$} & \multicolumn{3}{c|}{ Sum wage (CNY) } \\
\cline { 2 - 8 } & $\mathrm{fo}$ & $\mathrm{f}_{1}$ & $\mathrm{X}_{0}$ & $\mathrm{X}_{0} \mathrm{f}_{0}$ & $\mathrm{X}_{1} \mathrm{f}_{1}$ & $\mathrm{X}_{1} \mathrm{f}_{0}$ & $\mathrm{X}_{0} \mathrm{f}_{1}$ \\
\hline Bank & 239.0 & 2436.5 & 29292.5 & 44017.5 & 7000907.5 & 107248638.8 & 731371176.3 \\
\hline Insurance & 6.5 & 72.0 & 53473.5 & 114250.5 & 344904.1 & 8226036.0 & 3850092.0 \\
\hline Securities & 41.3 & 500.0 & 26144.5 & 34040.5 & 1079767.9 & 17020250.0 & 13072250.0 \\
\hline $\begin{array}{c}\text { Other } \\
\text { financial }\end{array}$ & 4.2 & 46.0 & 45078.0 & 63218.0 & 189327.6 & 2908028.0 & 2073588.0 \\
\hline
\end{tabular}


According to the above data, the calculation can have to finance all worker average wage and the change degree and buy-backs.

$$
\begin{aligned}
& \overline{k_{\text {var } i a b l e}}=\frac{\frac{\sum x_{1} f_{1}}{\sum f_{1}}}{\frac{\sum x_{0} f_{0}}{\sum f_{0}}}=\frac{\frac{135402952.8}{3054.5}}{\frac{8614907}{291}}=149.74 \% \\
& \frac{\overline{\sum x_{1} f_{1}}}{\sum f_{1}}-\frac{\sum x_{0} f_{0}}{\sum f_{0}}=44329-29604.5=14724.5
\end{aligned}
$$

By the calculation, the worker average wage of China's financial industry in general is on the rise, and the growth of buy-backs is $14724.5 \mathrm{CNY}$. Though the above analysis, it is easy to see our country financial industry workers in recent years, the quantity and the labor remuneration is present a significant growth trend, other insurance industry financial industry increased significantly, and the bank employs growth is relatively slow.

\section{Conclusion}

Enterprise financial statistics can not only provide financial information, the real value is that both provides corporate financial information, make the enterprise managers find the problems existing in the enterprise management, also lies in its effective measure enterprise future cash flow, stock and risk size, and help decision makers choose the investment direction and investment methods, scientific planning of the enterprise future development, enterprise financial statistics will occupy more important position especially under the modern enterprise system. Using various methods to the enterprise financial and statistical analysis is advantageous to the enterprise reasonable allocation and effective use of the funds and avoid risk, to promote the virtuous circle of funds, in the competition to the initiative to obtain the greatest return on capital which is the ultimate goal of enterprise statistics.

The purpose of enterprise fixed assets statistical significance is to provide the data for corporate leadership, in order to grasp the situation, also can facilitate the supervision of the masses, cadres to prevent for individual devour, thus make the enterprise fixes assets to protect, the relevant contents of statistics must to has a beginning and an end, through regular and long-term accumulation, objective and true statistics had got the original number.

The important work is to research and analyze statistics, summing up experience and find problem, solving problem and improve their work. To benefit for the enterprise or the superior and provide satisfactory services and help enterprises to improve the management of fixed assets and make use of the work, make the statistical work is to be provide service for the enterprise, to provide services for the purpose of the socialist modernization construction.

Meaning according to under the socialist market economy system and statistical investigation method of fusion trend of statistical system reform trend, in the social and economic statistics of Chinese medicine application scope and depth increase the method of mathematical statistics, we can be better used in economic management improve the speed of economic development and improve the work efficiency.

\section{References}

[1] Wei Zhang: Statistical Basis and Practice (Economic Science Press, Chinese 2010), p.72-103.

[2] Weihua Wang, the importance of statistical work by Enterprise financial analysis, China High Tech Enterprises, Vol. 17 (2015) No.20, p.187-188.

[3] Fan Yang, The new accounting standards impact on financial statistics accounting work, Money 
China, (2010), p.142.

[4] Jiandong Liu, about the statistical work of enterprise financial, Enterprises Forum, Vol. 2 (2016) No.58, p.81.

[5] Yanli Teng, Statistical work of enterprise fixed assets, Statistics and Consulting, (2002), p.37.

[6] Cangli Zhang, The gap about present situation between the financial statistics of our country and GDDS, Financial teaching and research, (2003) No.4, p.19-20.

[7] Xi Zhang, The analysis of the status quo of monetary and financial statistics, Times Finance, (2012) No.6, p.104.

[8] Jiadan Bai, Contemporary economic management in statistical application, Economics Estates, (2006), p.15.

[9] Yuhan Fu, The labor statistical analysis of China's financial industry, Financial View, (2009), p.34-35.

[10]Xiuzhi Li, Introduction to strengthen labor statistics some assumptions, Hi-Tech of China, (2008), p.317. 